\title{
How multidisciplinary are multidisciplinary team meetings in cancer care? An observational study in oncology departments in Flanders, Belgium
}

This article was published in the following Dove Medical Press journal: Journal of Multidisciplinary Healthcare

\author{
Melissa Horlait ${ }^{1}$ \\ Saskia Baes' \\ Sophie Dhaene ${ }^{2}$ \\ Simon Van Belle ${ }^{3}$ \\ Mark Leys' \\ 'Vrije Universiteit Brussel (VUB), \\ Department of Public Health, \\ Research Group Organisation, Policy \\ and Social Inequalities in Health Care \\ (OPIH), 1090 Brussels, Belgium; ${ }^{2} \mathrm{AZ}$ \\ Sint-Elisabeth Ziekenhuis, Department \\ of Oncology, 9620 Zottegem, \\ Belgium; ${ }^{3}$ Ghent University Hospital, \\ Department of Medical Oncology, \\ 9000 Gent, Belgium
}

Background: In current cancer care, multidisciplinary team meetings (MDTMs) aim at uniting care professionals from different disciplines to decide upon the best possible treatment plan for the patients based on the available scientific evidence. In Belgium, the multidisciplinary approach is mandatory and formally regulated since 2003. Current research indicates that MDTMs are not always truly multidisciplinary, ie, with a mix of medical as well as paramedical disciplines, and that the medical profession (physicians and medical specialists) tends to dominate the interaction in MDTMs. To ensure that MDTMs can benefit from their diverse membership to achieve their full potential, significant attention should be devoted to the multidisciplinary character of these meetings. The aim of this study is to explore and describe the multidisciplinary character in MDTMs and how it is actually shaped in practice in different Flemish medical oncology departments.

Methods: For this study, we carried out an observational comparative case study. We studied 59 multidisciplinary team meetings at inpatient medical oncology departments in five different Belgian hospitals (academic as well as general) and explored multidisciplinarity and how it is actually shaped in practice.

Results: The study is unique in identifying and analyzing three distinct types of MDTMs. The analysis of the three types revealed an inconsistent and, at times, contradictory picture of multidisciplinary team meetings. The findings also align with previous studies arguing that MDTMs in oncology are typically driven by doctors, with limited input of nurses and other nonmedical staff in which decisions are argued on biomedical information and far less consideration of psychosocial aspects.

Conclusion: The concept of a MDTM should not merely be a group of care professionals who work essentially independently and occasionally liaise with one another. Yet, this study has shown a worryingly low awareness of the true character of multidisciplinarity, particularly among medical disciplines.

Keywords: medical oncology, multidisciplinary teams, interprofessional care, qualitative research, health services research

\section{Introduction}

In current cancer care, multidisciplinary team meetings (MDTMs) aim at uniting care professionals from different disciplines to decide upon the best possible treatment plan for the patients based on the available scientific evidence. ${ }^{1,2}$ In Belgium, the multidisciplinary approach is mandatory and has been formally regulated since $2003 .{ }^{3-5}$ Since the introduction of the legal framework, the proportion of cancer patient cases discussed within MDTMs continuously increases in oncology departments. ${ }^{6,7}$

MDTMs are found to foster adherence to clinical practice guidelines ${ }^{8}$ and can positively influence clinical decision-making..$^{9-14}$ They induce better team performance after 
case discussion, ${ }^{15}$ more accurate diagnoses, ${ }^{16,17}$ and increased screening rates for clinical trials. ${ }^{18}$ Multidisciplinary teams also reach faster collaborative decisions during their meeting, which avoids delays to treatment. ${ }^{19}$ Evidence for the effectiveness of MDTMs in terms of patient outcomes is ambiguous. ${ }^{9,20}$ Some studies found that MDTMs improve patients' quality of life and even survival. ${ }^{21,22}$ Other research found little association of the implementation of MDTMs with patient quality or survival. ${ }^{8}$ These mixed findings can probably be partly explained by the fact that patient outcomes are affected by a wider range of factors not limited to multidisciplinary team management alone. ${ }^{23}$

The literature describes tumor boards, multidisciplinary cancer conferences, or multidisciplinary case reviews interchangeably without differentiating purpose and working practices. ${ }^{24}$ International research also does not pay much attention to the organizational dimension of MDTMs. It can be assumed, however, that organizational embeddedness may impact on the structure of the meeting, membership, approach, purpose, atmosphere, and decision-making processes. ${ }^{24}$

Further, research does not always distinguish carefully between groups and teams. The concept of a multidisciplinary team should not merely be a group of different care professionals who work essentially independently and occasionally liaise with one another. Teams are defined as two or more professionals interacting dynamically, interdependently, and adaptively toward a common, valued goal. ${ }^{25}$ Other concerns arise with regard to the concept of multidisciplinarity as there are a few studies indicating that that the medical profession (physicians and medical specialists) tends to dominate the interaction in MDTMs. ${ }^{26-28}$

The aim of this study is to explore and describe the multidisciplinary character in MDTMs and how it is actually shaped in practice in different Flemish medical oncology departments.

\section{Methods}

\section{Study design}

This study is part of a larger research project focusing on multidisciplinary collaboration in medical oncology departments and partly aligns with a previously published study protocol. ${ }^{29}$ For this study, we carried out an observational comparative case study. ${ }^{30}$ Data were collected by means of nonparticipant observations to obtain an insider view about behavior, communication patterns, and other interactions between participants in real practice to identify the emerging characteristics of multidisciplinary collaboration in oncology meetings. As observers, we did not interfere with the work of the team. ${ }^{31-34}$

\section{Units of analysis}

MDTMs are operationalized as formally organized team meetings where medical (physicians) and nonmedical (nonphysicians) disciplines meet (whether physically in one place, by videoconferencing, or by teleconferencing) to discuss patient cases and decide upon patient management. For this study, all types of multidisciplinary meeting arrangements in which patients' cases were discussed in teams were observed.

We focused on inpatient medical oncology departments in five different hospitals in Flanders, Belgium. We included two academic hospitals (with a number of beds varying from 700 to more than 1,000 beds) and three general hospitals (with a number of beds varying from 300 to 900), purposively chosen to obtain a view on multidisciplinary work in general, specialized, and highly specialized facilities. Both academic hospitals have a medical oncology department centralized at one campus with a large oncological care team even including medical trainees. As regards the general hospitals, the medical oncology department was spread over several campuses with a smaller team headed by only one medical oncologist.

\section{Data collection}

Two researchers (MH and SD) observed MDTMs individually and independently. Data were collected by audiotaping the meetings and taking field notes during the meetings. The audiotapes of the meetings served as a support for filling observation gaps, clarifying, and validating what was being observed. ${ }^{35}$ Field notes were taken using a supportive tool with predesigned dimensions such as: 1) goal of the meeting; 2) frequency; 3) duration; 4) composition; 5) active participation of the different team members; 6) team members' role during the meetings; and 7) topics discussed during the meeting. Intermediate reflections and preliminary findings were regularly discussed within the project team during the data collection. ${ }^{36}$ The template was adapted when new dimensions emerged inductively form the observations. ${ }^{37,38}$

\section{Data analysis}

Data collection and data analysis are integrated in an iterative reflexive process and were concurrent (the iterative cycle of qualitative research)..$^{38}$

The researchers' written field notes from the observations were used as a starting point for the analysis. Preliminary thematic analyses were performed after each observation and used to support the subsequent observations to expand on emerging issues or validate hypotheses within the problem statement. The inductive comparative analysis took form through a process of fine-tuning codes and themes or issues in a process of researcher and data triangulation 
and a validation strategy. ${ }^{38}$ The two researchers ( $\mathrm{MH}$ and $\mathrm{SD})$ independently coded the data thematically and then discussed and compared emerging categories, subcategories, and interpretations of the findings. In cases of disagreement, data were reviewed by both authors and the project team was consulted.

\section{Ethics approval and informed consent}

Ethics approval for this study was given by the central Medical Ethics Commission of the Brussels University Hospital (BUN 143201318799). Additional approval has been obtained from the participating organizations. All data from this study are anonymized and stripped of all sensitive personal and patient identifiers. Additional consent from the participants is obtained. Digital audiofiles are stored on a secured laptop and access to the data is only granted to the project team.

\section{Results}

In the selected oncology departments, two general types of MDTMs occur: 1) those to discuss patient cases; and 2) those to discuss organizational aspects or practical arrangements of the department. The latter were excluded for this study.

Overall, 59 MDTMs discussing patient cases were observed and analyzed.

\section{Taxonomy of MDTMs at inpatient medical oncology departments}

To obtain an overall picture of all multidisciplinary team activities at inpatient medical oncology departments, we first made a taxonomy of all different types of MDTMs to clarify the commonalities and differences. We observed three types of MDTMs: the multidisciplinary oncology consultation (MOC); the patient ward round; and the ward meeting. We differentiate the characteristics of the meetings according to the following inductively identified dimensions, presented in Table 1.

Table I Taxonomy of different types of MDTMs at inpatient medical oncology departments

\begin{tabular}{|c|c|c|c|c|}
\hline & & MOC & Patient ward rounds & Ward meeting \\
\hline \multirow[t]{3}{*}{ Participants } & $\begin{array}{l}\text { Medical } \\
\text { disciplines }\end{array}$ & $\begin{array}{l}\text { Internal hospital members: MOC } \\
\text { coordinator, physicians from } \\
\text { different medical subdisciplines } \\
\text { (medical oncology, surgical oncology, } \\
\text { pathology, nuclear medicine, } \\
\text { radiology, medical internist(s) of the } \\
\text { affected organ(s)), medical trainee(s) } \\
\text { External to hospital members: } \\
\text { general practitioner }\end{array}$ & Oncologist, medical trainee(s) & Oncologist(s), medical trainee(s) \\
\hline & $\begin{array}{l}\text { Paramedical } \\
\text { disciplines }\end{array}$ & Nurse specialist(s), psychologist & $\begin{array}{l}\text { (Head) nurse, pharmacist, nurse } \\
\text { administrator }\end{array}$ & $\begin{array}{l}\text { (Head) nurse, psychologist(s), } \\
\text { social worker(s), nutritionist(s), } \\
\text { palliative care specialist nurse(s), } \\
\text { physiotherapist }\end{array}$ \\
\hline & $\begin{array}{l}\text { Other } \\
\text { professions }\end{array}$ & Data manager & & \\
\hline Aim & & $\begin{array}{l}\text { To discuss patient cases and } \\
\text { recommend an evidence-based } \\
\text { treatment plan for each individual } \\
\text { patient }\end{array}$ & $\begin{array}{l}\text { To discuss the patient's daily condition, } \\
\text { physical functioning, or problems, } \\
\text { review available test results to evaluate } \\
\text { the plan of care, including cancer } \\
\text { treatments, and tentative discharge } \\
\text { plans to coordinate the plan of care } \\
\text { among the different care professionals }\end{array}$ & $\begin{array}{l}\text { To discuss the overall patient } \\
\text { cases of the hospitalized patients }\end{array}$ \\
\hline Timing & & Weekly/fortnightly & Daily & Weekly \\
\hline $\begin{array}{l}\text { Topics } \\
\text { discussed }\end{array}$ & & $\begin{array}{l}\text { Age and gender of patient, diagnosis, } \\
\text { tumor-staging based on clinical and } \\
\text { diagnostic information, comorbidities, } \\
\text { prior treatment(s) }\end{array}$ & $\begin{array}{l}\text { Patients' physical condition, patients' } \\
\text { daily functioning, complications or } \\
\text { problems, medication (changes), } \\
\text { progress of the treatment plan, mental } \\
\text { well-being, or psychological issues }\end{array}$ & $\begin{array}{l}\text { Medical information such } \\
\text { as patients' medical history, } \\
\text { diagnosis reasons for admission, } \\
\text { physical functioning, nonmedical } \\
\text { information such as psychosocial } \\
\text { characteristics }\end{array}$ \\
\hline $\begin{array}{l}\text { Decision- } \\
\text { making } \\
\text { process }\end{array}$ & & $\begin{array}{l}\text { Information exchange and decision- } \\
\text { making }\end{array}$ & $\begin{array}{l}\text { Information exchange and decision- } \\
\text { making }\end{array}$ & $\begin{array}{l}\text { Information exchange, } \\
\text { deliberation, and decision-making }\end{array}$ \\
\hline
\end{tabular}

Abbreviation: MDTM, multidisciplinary team meeting; MOC, multidisciplinary oncology consultation. 


\section{The multidisciplinary oncology consultation}

The MOC is the only formal, legally regulated type of MDTM within the Belgian oncology context. It includes a financial incentive for the participating physicians. This type of MDTM was created in 2003 to foster multidisciplinary consultation between care professionals within oncology departments and to ensure a systematic transparent approach across all institutions. A MOC is requested by the treating physician (usually the general practitioner or organ specialist of the hospital). The MOC is legally described as a meeting per individual patient but because of organizational convenience these are clustered in a collective meeting moment for all patients at stake, generally per tumor group, known as "MOC meetings." Most of the MOC meetings are organized weekly; for some tumor groups with fewer patients, they are fortnightly. The aim of the MOC meetings is to agree within the team on the diagnosis and to recommend a treatment plan (grounded in evidence) for each individual patient.

Belgian law states that the MOC must be chaired by a (medical) MOC coordinator (preferably with specific oncological competence) with participation of at least four different medical specialists (eg, radiotherapy, surgery, organ specialism, or pathology) who belong to the hospital staff (intra-muros participants) and one extra-muros participant (eg, the general practitioner or the treating physician of the patient if he/she is not part of the hospital team).

For all departments, the MOC meetings were primarily attended by hospital physicians from several medical subdisciplines and by an oncology nurse specialist(s). Medical trainees also participated in academic hospitals. In one general hospital an external general practitioner physically participated, in some other cases the general practitioner participated via videoconference. In another general hospital, a social worker attended the meeting. In two academic departments a data manager always participated for regulative reasons. The law makes the data manager responsible for the information flow between the hospitals and the Belgian Cancer Registry to evaluate the adherence to clinical guidelines as well as to assess the implementation of the MOC decisions. In only one academic hospital, a psychologist attended the meetings. The size of the group in MOC meetings varied widely by tumor group but also by hospital. Generally, the group of participants was deemed to be larger in the academic hospitals.

The routine of the MOC meetings can be disentangled into a phase of information exchange followed by a decisionmaking process on the treatment plan of the patient. First, the physicians predominantly report and discuss medical information. Mainly, medical information and almost always the patient's age and gender are shared. In most cases, the "requesting physician" briefly presents the patient's medical case with diagnostic information (pathology and nuclear medicine) and clinical information (including comorbidities and prior treatments). Very few psychosocial characteristics of the patient were reported. In some cases, the patient's general state of well-being was mentioned.

After the information-sharing phase, a decision-making process takes form on further diagnostic procedures and on treatment recommendations, grounded in evidence-based clinical guidelines available per hospital. For all hospitals, decisions were made either by the coordinator of the meeting or the head physician of the subspecialty, or jointly by all attending physicians.

Trainees participated in the exchange of medical information but did not play a prominent role in the decision-making process.

In none of the meetings did the nonmedical disciplines contribute actively to the provision of information or to the decision-making process.

\section{Patient ward rounds}

The patient ward round is a daily core activity in the observed departments. The primary aim of the ward rounds is to provide a daily occasion for the care team to review and integrate information as a group for the daily follow-up of the patients. They are usually conducted in the morning.

Mostly, the patient ward round is prepared in the nursing room or in a separate available space. Next, the multidisciplinary ward round team travels from bed to bed to review patient progress. The team updates itself on each patient's condition through discussion and chart review, and decides upon the patient's plan for the day.

In all general hospitals, the oncologist leads the rounds with a (head) nurse in attendance. In the academic hospitals, medical trainees conducted the patient ward rounds, sometimes under the supervision of the senior oncologists. In one department, a pharmacist and a data manager participated during the patient ward rounds. The size of the group of participants depended on the number of disciplines participating, varying from a minimum of three participants to a maximum of five.

The ward rounds begin with the (head) nurse presenting the most pertinent details of the patient and any recent changes (complications, medication changes, progress of the treatment plans). In some cases, the mental well-being 
or psychological issues were reported. Patients' reflections and considerations were collected at the bedside.

Decisions on the daily functioning of the patient were made by the oncologist or the medical trainee leading the patient rounds. Decisions regarding changes of the overall treatment plan of the patient were not observed during these rounds.

\section{Ward meetings}

Ward meetings are organized to discuss the hospitalized patient cases with all representatives of the care team. Multiple medical and nonmedical disciplines (such as oncologists, medical trainees, (head) nurse(s), psychologists, social workers, nutritionists, and palliative care specialists) attend this meeting. In one department, a physiotherapist also attends the meeting. The size of the group was generally larger compared to the previous types of meetings.

All attendees actively provide input from the perspective of their discipline. The goal of the ward meetings is to ensure that the multidisciplinary team collectively works toward a common care plan, addresses potential barriers to the patient's care plan, and prepares an eventual discharge.

Medical information provided by medical professions was frequently complemented with nonmedical information such as psychosocial characteristics (occupation, family situation or social context, disease understanding or compliance, and mental resilience) by other professions. This additional information impacts on the decision-making process of a treatment plan as we observed that decisions were adapted based on nonmedical information. In these meetings more time was spent on multidisciplinary deliberation, in which medical records were supplemented with psychosocial information on the patients and their personal preferences with regard to possible treatment plans were discussed among all attendees.

\section{Analysis of the multidisciplinary nature of MDTMs at inpatient medical oncology departments}

In all departments, MOC meetings were more formally and procedurally organized following a fixed, sequential pattern of: 1) case presentation initiated by the requesting physician or by the MOC coordinator; 2) provision of additional information from the pathologist, radiologist, or other physicians who had been involved in the diagnostic activities; 3) discussion of the possible treatment options; and 4) decisionmaking (with consolidation by the MOC coordinator).
Considerable time during the MOC meetings was spent on tumor-staging, involving highly medical jargon. Demographic aspects such as age and gender were mentioned usually as a means to introduce the patient. Patient treatment preferences were rarely discussed, let alone taken into account in the subsequent decision-making process.

A few nonmedical disciplines (psychologists and oncology nurse specialists) attend the MOC meeting; however, they had little or no input during the discussions.

In the other types of MDTMs the atmosphere and approach was more informal and meetings were less structured, yet dynamic.

In other MDTMs, we observed a more equal participation of medical as well as nonmedical disciplines. Especially during the ward meetings, a broad range of nonmedical disciplines was present, ie, nurses, psychologists, social workers, nutritionists, palliative care nurses, and physiotherapists. Medical information was complemented with psychosocial aspects such as occupation of the patients, family situation or social context, disease understanding or compliance, mental resilience, and patients' care or treatment preferences. The palliative care nurses frequently mentioned the patients' end-of-life preferences and actively took up the leading role in introducing the subject of palliative care.

\section{Organizational factors affecting the different MDTMs}

One of our key observations, seldom described in other research, is that the content of what is being discussed during the different types of MDTMs is interdependent. Outcomes of one type of MDTM were often included in the discussion of other meetings. In some cases, treatment plans decided upon during the MOC meeting were modified during the ward meeting when additional nonmedical information was added to the discussion.

Academic hospitals provide an educational environment for medical trainees to acquire hands-on clinical experience during their training. Through a process of graduated responsibility - whereby trainees are expected to take on increased responsibility as they acquire greater competence - medical trainees are an additional layer of care professionals creating additional differentiation in the organization of care. In academic hospitals, more care professionals (from the same discipline) are involved in the different MDTMs, albeit with differentiated training levels. This higher organizational complexity seems to affect the information-exchange process 
during the meetings. We observed that the patients' information was more fragmented as more trainees were present since they all separately added particular input to the informationsharing process. Moreover, MDTMs equally serve as a learning opportunity for the attending trainees whereby clinical results or possible treatment options were more extensively discussed and diagnostic dilemmas explored, very often referring to the scientific background of decisions and recent medical literature. This had a particular impact on the MOC meetings being reduced to an exclusively medical-focused meeting.

The presence of medical trainees also impacts the composition of MDTMs both in terms of quantity as well as for the division of tasks. In the observed academic departments, the daily patient ward rounds were fully delegated to the medical trainees (although still under the supervision of the senior physicians). As a consequence, sufficient time (more than in the other hospitals) was foreseen to conduct the rounds. In the nonacademic departments, all types of meetings are planned on top of the busy work schedule of the oncologists. As a result, for example, MOC meetings were often scheduled outside the core working hours such as early in the morning or late in the evening. Physicians attending these meetings seemed rather hasty to handle the patient cases, reducing the time spent on patient discussions and limiting the (kind of) information being shared during the discussions.

Administrative support, equipment, and facilities for the meetings differ between the academic and nonacademic hospitals. In the academic hospitals, every MOC meeting was attended by a data manager monitoring the patient cases discussed and providing technical support for the equipment for videoconferencing and projecting patient data. In none of the cases, however, did these actively contribute to the meetings.

\section{Discussion}

Multidisciplinary teams are considered the golden standard for cancer patient management and care. ${ }^{5,20-22,39}$ Comprehensive reforms were necessary to install and facilitate multidisciplinary care and have been completed in the organizational structure of healthcare delivery for oncology patients around the world, ${ }^{22,40-43}$ as in Belgium. ${ }^{3,4}$ These changes transformed healthcare services formerly based on individual physicians' decision-making into institutionally supported team-based approaches to treatment and care. ${ }^{21,44,45}$

To date, few articles have studied in real life how multidisciplinarity in cancer patient management and care may take form. In the present study, we studied 59 MDTMs at inpatient medical oncology departments in five different Belgian hospitals (academic as well as general) and explored multidisciplinarity.

First, this study is unique in identifying and analyzing three distinct types of MDTMs: the MOC; the patient ward round; and the ward meeting. The analysis of the three types revealed an inconsistent and, at times, contradictory picture of MDTMs. In particular for the MOC meetings, the only formally regulated (and financed) type of MDTM, this study has shown a worryingly low awareness of the true character of multidisciplinarity, particularly among medical disciplines. The legal framework may have had a positive impact on the implementation of the multidisciplinary approach in Belgian oncology, ${ }^{7}$ but the intentions of the policy-makers are not fully met or at least not as recommended in the guidelines for multidisciplinary cancer care., The rather "procedural" approach in the MOC meetings and the organizational choice of pooling of MOCs at particular moments (weekly or fortnightly) reduces the meeting to a routine of collecting biomedical information and staging of the disease to ground treatment decisions in available guidelines. Hence, the legal obligation to install MOC meetings has enhanced multidisciplinarity but seems to have the unintended consequence that organizational practices induce routinization and dominance in biomedical terms more than an in-depth deliberation of the patients' cases in all aspects including psychosocial information.

These findings with regard to multidisciplinarity align with previous studies arguing that MDTMs in oncology are typically driven by doctors, with limited input from nurses and other nonmedical staff (such as, eg, psychologists). ${ }^{46,47}$ Given the limited input from nursing or psychosocial professionals it becomes clear that information related to patient preferences and psychosocial aspects is discussed far less compared to biomedical information and was rarely taken into account when making treatment recommendations. ${ }^{16,27,48}$ These patterns are potentially problematic for MDTMs. ${ }^{49}$ To ensure that MDTMs can benefit from their diverse membership to achieve their full potential, significant attention should be devoted to the multidisciplinary character of these meetings. It has also been found in other types of healthcare teams that nurses are less confident about speaking up during ward round discussions, are reluctant to contribute to discussions, ${ }^{50}$ and tend only to contribute in response to direct questions from medical staff. ${ }^{51}$ In these studies, status hierarchy is pointed out as a determinant for this phenomenon - meaning that the existence of (perceived) status hierarchies within healthcare 
teams may affect meeting participants' expectations of one another, being translated into inequalities in interaction and opportunities to participate among the different team members. ${ }^{52-55} \mathrm{We}$ argue that more attention should be devoted to the participation of psychologists during the MDTMs. This professional group is underrepresented in the international literature, possibly because they are not consequently considered core members of MDTMs. Our findings, however, show that in addition to the nurses, psychologists may have a dedicated role during the meetings as they can potentially bridge the gap between higher and lower status members of the team, becoming an "additional mechanism" to enhance the uptake of psychosocial aspects and patient preferences in treatment decisions. ${ }^{49,56}$

This study also shows that the different types of MDTMs are interdependent moments which all contribute in a particular way to the framing of the overall "patient story." In that way, our findings support the idea that multidisciplinarity should not be studied as one-shot moments, but as a process of information exchange and reflection throughout various types of meetings involving different care professionals. At the same time, much more research will be needed on how this interdependency of meetings truly contributes to an integral appreciation of the oncological patient trajectory.

To the best of our knowledge, this is the first in-depth empirical study on the multidisciplinary character of multidisciplinary meetings in oncology. Notwithstanding the added value of this type of empirical research, an important methodological limitation of this study needs to be considered. We performed a purposive sampling of inpatient medical oncology departments within two academic hospitals and three nonacademic hospitals in one country, limiting the generalizability of the results for broader organizational contexts and health systems. Further research is needed to discover whether our findings are applicable across cancer care departments nationally and internationally, and replication of the main findings is needed before firm conclusions can be drawn. The risk of subjectivity should be considered in the context of other limitations as the two authors ( $\mathrm{MH}$ and SD) individually and independently observed the MDTMs. However, the field notes were taken during the observations using a supportive tool with predesigned dimensions. After each observation session, a debriefing with the project team was organized, enhancing the permeability of the researchers' understanding of the data gathered and developing awareness of possible preconceptions. Moreover, previous studies in the UK and other countries also using observational methods have arrived at similar conclusions, thereby lending validity to these results. ${ }^{16,44,47,56,57}$

\section{Conclusion}

The concept of a MDTM should not merely be a group of care professionals who work essentially independently and occasionally liaise with one another. Understanding the complex interrelationships between internal and external factors affecting MDTMs is challenging but indispensable to better understand and consequently improve the effectiveness. In particular, more empirical studies are needed to reveal the true reasons why these meetings fail to fully integrate all disciplines. Also, more empirical evidence to understand how team composition, hospital culture, and organizational or environmental factors can either directly affect MDTM performance or serve as key mediators or moderators to its success is needed. Lastly, we believe that these findings can be used as a basis for designing and implementing acceptable and thus implementable interventions aiming to enhance the input of psychosocial information and overcome the lack of patient preferences. In particular, tools such as decision aid checklists may be pivotal to ensure that MDTMs can benefit from their diverse membership to achieve their full potential.

\section{Acknowledgments}

The authors would like to thank the included departments for their cooperation and participation in this study. The study is part of a larger research project on communication and multidisciplinary collaboration in oncology departments that is funded by The Research Foundation - Flanders (FWO) (G035813N).

\section{Author contributions}

$\mathrm{MH}, \mathrm{SD}, \mathrm{SB}, \mathrm{SVB}$ and ML had substantial contributions to the conception and design of the study. $\mathrm{MH}$ and $\mathrm{SD}$ performed data collection, $\mathrm{MH}, \mathrm{SD}, \mathrm{SB}$ and $\mathrm{ML}$ performed the analysis and interpretation of the data. All authors took part in drafting the article or revising it critically for important intellectual content, gave final approval of the version to be published, and agreed to be accountable for all aspects of the work.

\section{Disclosure}

The authors report no conflicts of interest in this work.

\section{References}

1. Fleissig A, Jenkins V, Catt S, Fallowfield L. Multidisciplinary teams in cancer care: are they effective in the UK? Lancet Oncol. 2006;7(11):935-943.

2. Vinod SK, Sidhom MA, Delaney GP. Do multidisciplinary meetings follow guideline-based care? J Oncol Pract. 2010;6(6):276-281. 
3. Van Belle S. How to implement the multidisciplinary approach in prostate cancer management: the Belgian model. BJU Int. 2008;101(Suppl 2):2-4.

4. Verhoeven D, van Hoof E, Leto C, Van den Bogaert S, Degj LL. The Belgian cancer plan. Health Econ. 2010;4(6):264-267.

5. European Partnership Action Against Cancer consensus group, Borras $\mathrm{JM}$, Albreht T, et al. Policy statement on multidisciplinary cancer care. Eur J Cancer. 2014;50(3):475-480.

6. Callens M, van den Oever R. Quality improvement in cancer care: the multidisciplinary oncological consultation. Acta Chir Belg. 2006;106(5):480-484.

7. Vrijens F, Kohn L, Dubois C, Leroy R, Vinck I, Stordeur S. Ten years of multidisciplinary teams meetings in oncology: current situation and perspectives. Health Services Research (HSR) Brussels: Belgian Health Care Knowledge Centre (KCE). 2015. KCE Reports 239Cs. Available from: https://kce.fgov.be/sites/default/files/atoms/files/ KCE_239_team\%20meetings_oncology_Report_2.pdf. Accessed November 30, 2018.

8. Keating NL, Landrum MB, Lamont EB, Bozeman SR, Shulman LN, McNeil BJ. Tumor boards and the quality of cancer care. J Natl Cancer Inst. 2013;105(2):113-121.

9. Croke JM, El-Sayed S. Multidisciplinary management of cancer patients: chasing a shadow or real value? An overview of the literature. Curr Oncol. 2012;19(4):e232-e238.

10. van Hagen P, Spaander MC, van der Gaast A, et al; Rotterdam Oesophageal Tumour Study Group. Impact of a multidisciplinary tumour board meeting for upper-GI malignancies on clinical decision making: a prospective cohort study. Int J Clin Oncol. 2013;18(2):214-219.

11. Rao K, Manya K, Azad A, et al. Uro-oncology multidisciplinary meetings at an Australian tertiary referral centre-impact on clinical decision-making and implications for patient inclusion. BJU Int. 2014;114(Suppl 1):50-54.

12. Ung KA, Campbell BA, Duplan D, Ball D, David S. Impact of the lung oncology multidisciplinary team meetings on the management of patients with cancer. Asia Pac J Clin Oncol. 2016;12(2):e298-e304.

13. Leff DR, Ho C, Thomas H, et al. A multidisciplinary team approach minimises prophylactic mastectomy rates. Eur J Surg Oncol. 2015;41(8):1005-1012.

14. Schmidt HM, Roberts JM, Bodnar AM, et al. Thoracic multidisciplinary tumor board routinely impacts therapeutic plans in patients with lung and esophageal cancer: a prospective cohort study. Ann Thorac Surg. 2015;99(5):1719-1724.

15. Kee F, Owen T, Leathem R. Offering a prognosis in lung cancer: when is a team of experts an expert team? J Epidemiol Community Health. 2007;61(4):308-313.

16. Lamb BW, Brown KF, Nagpal K, Vincent C, Green JS, Sevdalis N. Quality of care management decisions by multidisciplinary cancer teams: a systematic review. Ann Surg Oncol. 2011;18(8):2116-2125.

17. Pillay B, Wootten AC, Crowe $\mathrm{H}$, et al. The impact of multidisciplinary team meetings on patient assessment, management and outcomes in oncology settings: a systematic review of the literature. Cancer Treat Rev. 2016;42:56-72.

18. McNair AG, Choh CT, Metcalfe C, et al. Maximising recruitment into randomised controlled trials: the role of multidisciplinary cancer teams. Eur J Cancer. 2008;44(17):2623-2626.

19. Stalfors J, Lundberg C, Westin T. Quality assessment of a multidisciplinary tumour meeting for patients with head and neck cancer. Acta Otolaryngol. 2007;127(1):82-87.

20. Coory M, Gkolia P, Yang IA, Bowman RV, Fong KM. Systematic review of multidisciplinary teams in the management of lung cancer. Lung Cancer. 2008;60(1):14-21.

21. Prades J, Remue E, van Hoof E, Borras JM. Is it worth reorganising cancer services on the basis of multidisciplinary teams (MDTs)? A systematic review of the objectives and organisation of MDTs and their impact on patient outcomes. Health Policy. 2015;119(4):464-474.

22. Kesson EM, Allardice GM, George WD, Burns HJ, Morrison DS. Effects of multidisciplinary team working on breast cancer survival: retrospective, comparative, interventional cohort study of 13722 women. BMJ. 2012;344:e2718.
23. Sevdalis N, Green JS. Urologic oncology: expanding the evidence for multidisciplinary team cancer care. Nat Rev Urol. 2014;11(12): 668-669.

24. Fennell ML, Das IP, Clauser S, Petrelli N, Salner A. The organization of multidisciplinary care teams: modeling internal and external influences on cancer care quality. J Natl Cancer Inst Monogr. 2010;2010(40):72-80.

25. Taplin SH, Weaver S, Chollette V, et al. Teams and teamwork during a cancer diagnosis: interdependency within and between teams. J Oncol Pract. 2015;11(3):231-238.

26. Lanceley A, Savage J, Menon U, Jacobs I. Influences on multidisciplinary team decision-making. Int J Gynecol Cancer. 2008;18(2):215-222.

27. Lamb BW, Sevdalis N, Arora S, Pinto A, Vincent C, Green JS. Teamwork and team decision-making at multidisciplinary cancer conferences: barriers, facilitators, and opportunities for improvement. World J Surg. 2011;35(9):1970-1976.

28. Raine R, Wallace I, Nic A'Bháird C, et al. Improving the effectiveness of multidisciplinary team meetings for patients with chronic diseases: a prospective observational study. Heal Serv Deliv Res. 2014;2(37): $1-172$.

29. Horlait M, Van Belle S, Leys M. Input of psychosocial information during multidisciplinary team meetings at medical oncology departments: protocol for an observational study. JMIR Res Protoc. 2018;7(2):e64.

30. Mays N, Pope C. Qualitative research: observational methods in health care settings. BMJ. 1995;311(6998):182-184.

31. Creswell JW. Research Design: Qualitative, Quantitative, and Mixed Methods Approaches. Thousand Oaks, CA: SAGE Publications; 2014.

32. Maxwell JA. Qualitative Research Design: An Interactive Approach. Thousand Oaks, CA: SAGE Publications; 2013.

33. Creswell JW. Research Design: Qualitative \& Quantitative Approaches. Thousand Oaks, CA: Sage Publications; 1994.

34. Williams M, Vogt WP. The SAGE Handbook of Innovation in Social Research Methods. Thousand Oaks, CA: Sage Publications; 2011.

35. Morse JM, Barrett M, Mayan M, Olson K, Spiers J. Verification strategies for establishing reliability and validity in qualitative research. Int J Qual Methods. 2002;1(2):13-22.

36. Finlay L, Brendan G, editors. Reflexivity: A practical guide for researchers in health and social sciences. Oxford: Blackwell Science, 2008.

37. Corbin J, Strauss A. Basics of Qualitative Research: Techniques and Procedures for Developing Grounded Theory. Thousand Oaks, CA: SAGE Publications; 2014.

38. Miles MB, Huberman AM, Saldaña J. Qualitative Data Analysis: A Methods Sourcebook. 3rd ed. Thousand Oaks, CA: SAGE Publications.

39. Taylor C, Munro AJ, Glynne-Jones R, et al. Multidisciplinary team working in cancer: what is the evidence? BMJ. 2010;340:c951.

40. Wright FC, Lookhong N, Urbach D, Davis D, McLeod RS, Gagliardi AR. Multidisciplinary cancer conferences: identifying opportunities to promote implementation. Ann Surg Oncol. 2009;16(10): 2731-2737.

41. Department of Health UK. Manual for Cancer Services. London; 2004. Available from: https://webarchive.nationalarchives.gov. uk/20120503144034/http://www.dh.gov.uk/prod_consum_dh/groups/ dh_digitalassets/@dh/@en/documents/digitalasset/dh_4135596.pdf. Accessed February 1, 2019.

42. American College of Surgeons Commission on Cancer. Cancer Progam Standards. Rev. ed; 2012. Available from: https://www.facs.org/ /media/ files/quality\%20programs/cancer/coc/programstandards2012.ashx. Accessed February 1, 2019.

43. McAvoy B. Optimising cancer care in Australia. Aust Fam Physician. 2003; 32(5):369-372.

44. Jalil R, Ahmed M, Green JS, Sevdalis N. Factors that can make an impact on decision-making and decision implementation in cancer multidisciplinary teams: an interview study of the provider perspective. Int J Surg. 2013;11(5):389-394.

45. Ruhstaller T, Roe H, Thürlimann B, Nicoll JJ. The multidisciplinary meeting: an indispensable aid to communication between different specialities. Eur J Cancer. 2006;42(15):2459-2462. 
46. Kidger J, Murdoch J, Donovan JL, Blazeby JM. Clinical decisionmaking in a multidisciplinary gynaecological cancer team: a qualitative study. BJOG. 2009;116(4):511-517.

47. Dew K, Stubbe M, Signal L, et al. Cancer care decision making in multidisciplinary meetings. Qual Health Res. 2015;25(3):397-407.

48. Lamb BW, Taylor C, Lamb JN, et al. Facilitators and barriers to teamworking and patient centeredness in multidisciplinary cancer teams findings of a national study. Ann Surg Oncol. 2013;20(5):1408-1416.

49. Horlait M, Van Belle S, Leys M. Multidisciplinary team meetings at medical oncology departments: an observational study on communication and the impact of organisational structures. In: Horlait M. editor. Palliative Care Communication in Oncology Departments in Flanders, Belgium. Brussels, Belgium: VUB Press; 2017.

50. Atwal A, Caldwell K. Do all health and social care professionals interact equally: a study of interactions in multidisciplinary teams in the United Kingdom. Scand J Caring Sci. 2005;19(3):268-273.

51. Busby A, Gilchrist B. The role of the nurse in the medical ward round. JAdv Nurs. 1992;17(3):339-346.

52. Lichtenstein R, Alexander JA, McCarthy JF, Wells R. Status differences in cross-functional teams: effects on individual member participation, job satisfaction, and intent to quit. J Health Soc Behav. 2004;45(3):322-335.
53. Nembhard IM, Edmondson AC. Making it safe: the effects of leader inclusiveness and professional status on psychological safety and improvement efforts in health care teams. J Organ Behav. 2006;27(7):941-966.

54. Satterstrom P, Polzer JT, Wei R. Reframing hierarchical interactions as negotiations to promote change in health care systems. In: Ayoko OB, Ashkansy NM, Jehn K, editors. Handbook of Conflict Management Research. Cheltenham, UK: Edward Elgar Publishing; 2014.

55. Ridgeway CL. Social status and group structure. In: Hogg MA, Tindale SR, editors. Blackwell Handbook of Social Psychology: Group Processes. Oxford, UK: Blackwell Publishers; 2008:352-375.

56. Sharma RA, Shah K, Glatstein E. Multidisciplinary team meetings: what does the future hold for the flies raised in Wittgenstein's bottle? Lancet Oncol. 2009;10(2):98-99.

57. Lamb BW, Sevdalis N, Mostafid H, Vincent C, Green JS. Quality improvement in multidisciplinary cancer teams: an investigation of teamwork and clinical decision-making and cross-validation of assessments. Ann Surg Oncol. 2011;18(13):3535-3543.
Journal of Multidisciplinary Healthcare

\section{Publish your work in this journal}

The Journal of Multidisciplinary Healthcare is an international, peerreviewed open-access journal that aims to represent and publish research in healthcare areas delivered by practitioners of different disciplines. This includes studies and reviews conducted by multidisciplinary teams as well as research which evaluates the results or conduct of such teams or health

\section{Dovepress}

care processes in general. The journal covers a very wide range of areas and welcomes submissions from practitioners at all levels, from all over the world The manuscript management system is completely online and includes a very quick and fair peer-review system. Visit http://www.dovepress.com/ testimonials.php to read real quotes from published authors. 